\title{
Increased central immunoreactive $\beta$-endorphin content in patients with Wernicke-Korsakoff syndrome and in alcoholics
}

\author{
J A Summers, P T Pullan, J J Kril, C G Harper
}

\begin{abstract}
$\beta$-endorphin, adrenocorticotrophin, and $\alpha$-melanocyte stimulating hormone were measured by radioimmunoassay in three areas of human brain at necropsy in seven subjects with Wernicke-Korsakoff syndrome and in 52 controls. Thiamin concentration in six brain areas was also measured. Mamillary body $\beta$-endorphin concentrations were significantly increased in those with the syndrome compared with controls, and those controls with high alcohol intake showed increased mamillary body $\beta$-endorphin compared with controls with low alcohol intake. Brain thiamin concentration was similar in both groups, with the exception of the brainstem, where it was reduced in subjects with WernickeKorsakoff syndrome. Thalamic $\beta$-endorphin in controls was inversely correlated with thiamin in frontal white matter, frontal cortex, parietal white matter and parietal cortex, while $\beta$-endorphin in the hypothalamus of patients was inversely correlated with thiamin in frontal cortex, parietal white matter, thalamus and brainstem. These results suggest that there is a disturbance of the endorphinergic system in Wernicke-Korsakoff syndrome which may be related to alcohol intake.
\end{abstract}

Ethanol may affect the metabolism of $\beta$ endorphin $(\beta$-EP) in the central nervous system (CNS). Ethanol ingestion for two to three weeks led to increased synthesis of $\beta$-EP, $\beta$ lipotropin $(\beta-\mathrm{LPH})$, and their precursor molecule, pro-opiomelanocortin (POMC), in the pituitary gland of rats. ${ }^{12}$ Acute ethanol in vivo was associated with pituitary release of $\beta$ EP. ${ }^{3}$ Conversely, $\beta$-EP pre-conditioning attenuated the acquisition of ethanol preference, ${ }^{4}$ suggesting that the CNS activities of $\beta$ EP and ethanol may be interdependent.

Administration of $\beta$-EP has repeatedly been shown to affect memory and learning. Low dose $\beta$-EP produced complete amnesia for two types of task in rats, ${ }^{56}$ whereas naloxone, a specific endorphin antagonist, facilitated memory function. Similar findings have recently been reported in chicks, ${ }^{7}$ and continue to be shown in rats. ${ }^{89}$ The sum of experimental evidence in animals and $\operatorname{man}^{1011}$ suggests that endogenous opioids have a major physiological role as amnesic agents.

Memory performance in rats is improved by adrenocorticotrophin (ACTH) and $\alpha$ - melanocyte stimulating hormone ( $\alpha$-MSH), which are also derived from POMC. ${ }^{1213}$ Similar but less predictable effects are found in man, ${ }^{14-19}$ where the predominant changes are on mood and selective attention.

The brain areas which contain the highest concentrations of POMC and its productsthat is, the hypothalamus, mamillary body, and thalamic nuclei ${ }^{20}$-are precisely the same areas most affected in Wernicke-Korsakoff syndrome. ${ }^{21}$ This disease, caused by thiamin deficiency and found almost exclusively in alcoholics, is characterised by profound memory impairment. We have previously reported decreased hypothalamic ACTH concentrations in rats with long term thiamin deficiency. ${ }^{22}$ In view of the colocalisation of central POMC product distribution and Wernicke-Korsakoff lesions, the putative roles of $\beta$-EP, ACTH, and $\alpha-\mathrm{MSH}$ in memory function; reported effects of ethanol on CNS $\beta$-EP metabolism; and the finding of central ACTH depletion in rat thiamin deficiency, this study was undertaken to measure POMC products in the human brain at necropsy and to relate these measurements to the presence of Wernicke-Korsakoff lesions, brain thiamin content, and alcohol intake during life.

\section{Methods}

Fifty nine cases were selected for study from a larger series of 120 necropsies. Selected cases had no neurological or neuropathological abnormalities except those relating to alcohol. Necropsies were performed at the Perth city coroner's department and Royal Perth Hospital. Brains were collected fresh and the weight and volume determined. The cerebellum and brainstem were removed at the level of the midbrain and the hemispheres divided sagittally. The left hemisphere was fixed for 14 days in $10 \%$ buffered saline after which it was embedded in agarose and cut at $3 \mathrm{~mm}$ intervals in the coronal plane. The cerebellum and brainstem (after the brainstem block was removed) were also fixed and sectioned. Macroscopic and microscopic examinations, including the cerebellum, midbrain, pons, medulla, hippocampus, thalamus, hypothalamus, mamillary body and numerous areas of the cortex, were performed.

The right hemisphere was dissected fresh and the areas for study placed in preweighed glass phials, reweighed, and frozen at $-70^{\circ} \mathrm{C}$. Samples of tissue were taken from: the mamillary body-entire right mamillary body, the frontal cortex-superior frontal gyrus, \\ 6 September 1990
}


frontal white matter-deep white matter underlying the superior frontal gyrus, parietal cortex-precentral gyrus, parietal white matter-underlying precentral gyrus, hypothalamus and thalamus-from a cut into the basal ganglia at the level of the mamillary body, and brainstem-cross sectional slice of medulla at the inferior olivary nuclei.

To determine the alcohol intake, cause of death, nutritional state and vitamin tablet consumption, clinical information was collected from hospital notes, necropsy reports, and questionnaires sent to the relatives of the deceased. No case was included which had any history or evidence of a neurological disease or a head injury. All cases of Wernicke's encephalopathy were confirmed by examining the contralateral hemisphere histologically.

\section{TISSUE EXTRACTION FOR NEUROPEPTIDE ANALYSIS}

The extraction procedures for $\beta$-EP, ACTH, and $\alpha-\mathrm{MSH}$ were identical and were based on the method of Krieger et al. ${ }^{23}$ Tissue samples were homogenised for 10 seconds in $600 \mu \mathrm{l}$ $100 \mathrm{mM}$ hydrochloric acid. After the addition of $600 \mu \mathrm{l} 80 \%$ acetone in $100 \mathrm{mM}$ hydrochloric acid the samples were homogenised for a further 10 seconds. After centrifugation (6000 $\times g$ for 10 minutes) $800 \mu l$ of supernatant was transferred to a clean polypropylene tube and dried under nitrogen in a water bath at $60^{\circ} \mathrm{C}$. The dried extract was reconstituted in $100 \mu \mathrm{l} 100 \mathrm{mM}$ hydrochloric acid before the addition of $900 \mu 150 \mathrm{mM}$ sodium phosphate buffer, $\mathrm{pH} \mathbf{7 \cdot 4}$ (containing $0.25 \%$ human serum albumin (Commonwealth Serum Laboratories, Melbourne, Australia), and $0.5 \%$ 2-mercaptoethanol (Calbiochem, USA)). The $\mathrm{pH}$ was checked with phenol red indicator, and if necessary, samples were neutralised with $100 \mathrm{mM} \mathrm{NaOH}$. Average recoveries at $100 \mathrm{pg} /$ assay tube were $107 \%, 90 \%$, and $84 \%(\mathrm{n}=5)$ for $\beta$-EP, $\mathrm{ACTH}$, and $\alpha-\mathrm{MSH}$, respectively.

\section{RADIOIMMUNOASSAY}

Brain extracts were assayed at appropriate dilutions in three radioimmunoassays based on the methods of Rees $e t a^{24}$ and Jeffcoate $e t$ $a l .^{25}$ Separation of bound and unbound ligand was achieved by second antibody precipitation rather than the charcoal used in the original methods. The $\beta$-EP antiserum (BNSII), raised in rabbits, was used at a final incubation dilution of 1 in 20000 and cross reacted equally on a weight to weight basis with $\beta$ $\mathrm{LPH}$, to a slight degree with $\mathrm{ACTH}_{4-10}$ $(0.005 \%), \quad \alpha$-endorphin $(0.003 \%)$, and $\alpha$-MSH $(0.0003 \%)$, but not at all with $\mathrm{ACTH}_{1-39}, \mathrm{ACTH}_{1-24}, \mathrm{ACTH}_{18-39}$ (CLIP) or met-enkephalin. The ACTH antiserum, raised in sheep and used at a final incubation dilution of 1 in 12000 , was directed at the middle portion of the ACTH molecule, and showed cross reactivity with $\mathrm{ACTH}_{1-24}$ $(100 \%), \alpha-\mathrm{MSH}(0.5 \%)$, and $\beta$-EP $(0.004 \%)$. A commercial antibody used for the $\alpha-\mathrm{MSH}$ assay (UCB Bioproducts, Belgium I660/001, Batch 203) at a final dilution of 1 in 600 gave significant cross-reactivity only with $\mathrm{ACTH}_{1-24}(0 \cdot 15 \%)$ and CLIP $(0 \cdot 02 \%)$.

Resulting assay sensitivities were $1.0 \mathrm{pg} / \mathrm{mg}$ for $\beta$-EP and $\alpha-M S H$ in the hypothalamus, $0.4 \mathrm{pg} / \mathrm{mg}$ for $\beta$-EP in the mamillary body and thalamus, and $0.5 \mathrm{pg} / \mathrm{mg}$ for ACTH. All samples were assayed blind.

Measurement of thiamin was performed by an automated method using Lactobacillus fermenti ${ }^{26}$ based on an earlier manual microbiological method. ${ }^{27}$

\section{DATA ANALYSES}

Results for brain thiamin concentration are expressed as mean \pm standard error of the mean, and were compared using Student's $t$ test for unpaired data. All other data, which were not normally distributed according to the Kolmogorov-Smirnov one sample test, were transformed using natural logarithms before comparison of geometric means using Student's $t$-test. Results are expressed as geometric mean with standard deviation of the geometric mean. Log transformed data were used to calculate Pearson's partial correlation coefficients, where the subject's age, body mass index (BMI), and delay after necropsy were held constant.

The concentration of neuropeptides in some brain regions is extremely low in terms of present assay sensitivities; where undetectable results occurred, they were assigned a value corresponding to half the assay sensitivity, for the purposes of calculating mean values. In control subjects this was the case in six of the thalamic $\beta$-EP samples, in 19 mamillary body ACTH, and 24 thalamic ACTH samples, and virtually all of the thalamic $\alpha$-MSH samples, which have been reported as "most undetectable". Samples from subjects with Wernicke-Korsakoff syndrome were undetectable only twice. Where this occurred values were assigned and treated as described above. All undetectable results were omitted from calculations of correlation coefficients.

The influence of alcohol intake on mamillary body $\beta$-EP was studied by dividing control subjects into three categories, depending on whether daily alcohol intake in grams of pure ethanol was $<20 \mathrm{~g} /$ day (low), $20-80$ $\mathrm{g} /$ day (moderate), or $>80 \mathrm{~g} /$ day (alcoholic). Five control subjects were excluded due to there being no information available regarding their alcohol intake, with the remainder spread over the three categories in the proportions 21:10:15. The entire group with Wernicke-Korsakoff syndrome was alcoholic according to this system of classification.

\section{Results}

Of the 59 subjects, seven had lesions diagnostic of Wernicke-Korsakoff syndrome, of which five were chronic and two acute on chronic. Mean age of the remaining subjects was 51.8 $(2 \cdot 3)$ years, with those with Wernicke-Korsakoff being $62.0(6.0)$ years (NS). The mean BMI of both groups was in the normal weight range. The control group comprised 42 males 
Table 1 Necropsy concentrations of $\beta$-endorphin, ACTH, and $\alpha-M S H$ in three midbrain areas of 52 controls $(C)$ and seven subjects with Wernicke-Korsakoff syndrome

\begin{tabular}{|c|c|c|c|}
\hline & Hypothalamus & Mamillary body & Thalamus \\
\hline \multicolumn{4}{|l|}{$\beta-E P$} \\
\hline $\begin{array}{l}\text { Controls } \\
\text { Wernicke-Korsakoff }\end{array}$ & $\begin{array}{l}99.48(0.35) \\
91.84(0.33)\end{array}$ & $\begin{array}{c}8.85(0.64) \\
17.64(0.65)^{\star}\end{array}$ & $\begin{array}{l}8 \cdot 67(1.22) \\
8 \cdot 17(1.26)\end{array}$ \\
\hline $\begin{array}{l}A C T H \\
\text { Controls } \\
\text { Wernicke-Korsakoff }\end{array}$ & $\begin{array}{r}8.08(0.74) \\
11.70(0.91)\end{array}$ & $\begin{array}{l}3.35(1.32) \\
2.34(0.76)\end{array}$ & $\begin{array}{l}1.30(0.50) \\
1.22(0.32)\end{array}$ \\
\hline $\begin{array}{l}x-M S H \\
\text { Controls } \\
\text { Wernicke-Korsakoff }\end{array}$ & $\begin{array}{l}17 \cdot 81(0.40) \\
17 \cdot 29(0.48)\end{array}$ & $\begin{array}{c}\text { Not measured } \\
,\end{array}$ & $\begin{array}{l}\text { Most } \\
\text { undetectable }\end{array}$ \\
\hline
\end{tabular}

Results are expressed as $\mathrm{pg} / \mathrm{mg}$ wet weight of brain tissue.

${ }^{\star} \mathrm{p}<0.01$.

Results are geometric mean with standard deviation of the geometric mean in parentheses.

and 10 females; the group with Wernicke-Korsakoff syndrome was exclusively male. Mean necropsy delay was the same in both groups (controls: $34.5(2.9)$ patients: $28 \cdot 5(2 \cdot 2)$ hours).

Mamillary body $\beta$-EP was increased in subjects with Wernicke-Korsakoff syndrome by a factor of $2(p<0.01)$ (table 1$)$. Mean mamillary body $\beta$-EP compared with alcohol intake is shown in the figure. There was a significant difference between the mean mamillary body $\beta$-EP values of the low intake group compared with the alcoholic group ( $p<0.05)$. The results of the group with Wernicke-Korsakoff syndrome were higher compared with the low $(p<0.01)$ and moderate alcohol intake $(p<0.05)$ groups. There were no other significant changes to POMC products in subjects with WernickeKorsakoff syndrome compared with controls.

Mean thiamin concentrations in the brain regions tested were not significantly changed in subjects with Wernicke-Korsakoff syndrome, with the exception of the brainstem, where it

\footnotetext{
Mamillary body $\beta$ endorphin content in necropsy human brain compared with habitual level of alcohol intake; Low $=<20$ g/day

$(n=21)$, Mod $=20-80$

g/day $(n=10)$, and

$A l c=>80 \mathrm{~g} /$ day

$(n=15)$. All subjects with Wernicke-Korsakoff syndrome $(W K)(n=7)$ were classified as alcoholics. Bars represent geometric means.

Standard deviations of the geometric means were $0.43,0.64,0.79$ and 0.65 respectively.
}

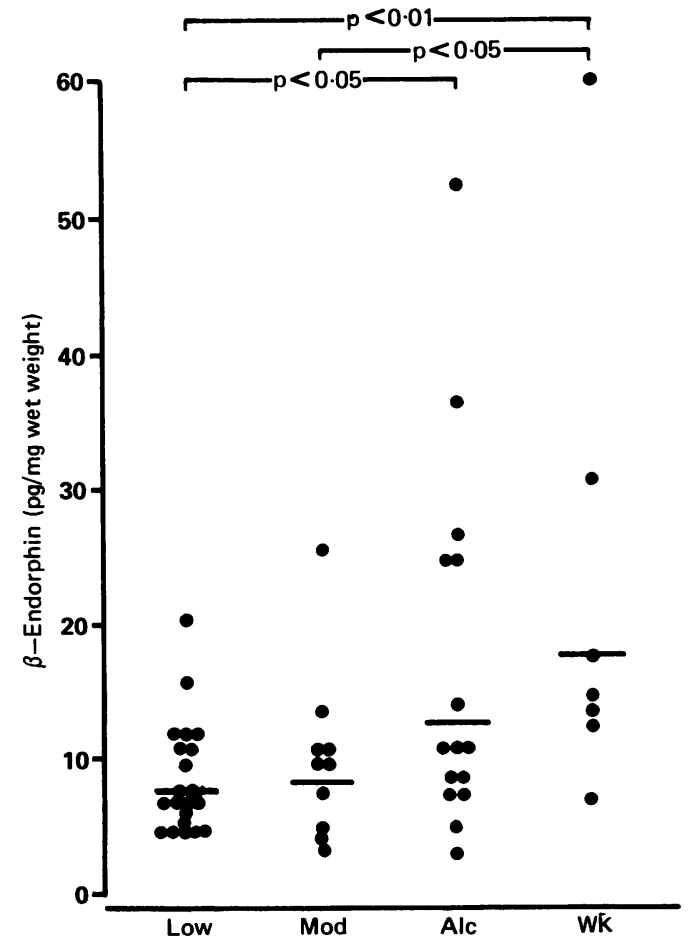

Table 2 Mean (SEM) thiamin concentrations in six brain areas of 52 controls and seven patients

\begin{tabular}{lll}
\hline & Controls & Patients \\
\hline Frontal white matter & $1.00(0.06)$ & $1.05(0.17)$ \\
Frontal cortex & $1.60(0.08)$ & $1.35(0.19)$ \\
Parietal white matter & $0.97(0.06)$ & $0.86(0.13)$ \\
Parietal cortex & $1.68(0.08)$ & $1.40(0.18)$ \\
Thalamus & $1.90(0.10)$ & $1.71(0.19)$ \\
Brainstem & $1.24(0.08)$ & $0.94(0.09)^{\star}$ \\
\hline
\end{tabular}

Results are expressed as $\mu \mathrm{g} / \mathrm{g}$ wet weight of brain tissue. ${ }^{\star} \mathrm{p}<0.02$.

was reduced ( $p<0.02$ ), (table 2 ). Thalamic $\beta$ EP was negatively correlated with thiamin in the frontal white matter $(r=-0.31$, $\mathrm{p}<0.01)$, frontal cortex $(\mathrm{r}=-0.30$, $\mathrm{p}<0.02)$, parietal white matter $(\mathrm{r}=-0.38$, $\mathrm{p}<0.005)$ and parietal cortex $(\mathrm{r}=-0.25$, $\mathrm{p}<0.05$ ) of control subjects. In patients, negative correlations between brain thiamin and $\beta$-EP concentrations were also seen in this case between $\beta$-EP in the hypothalamus and thiamin in frontal cortex $(\mathrm{r}=-0.71$, $\mathrm{p}<0.05)$, parietal white matter $(\mathrm{r}=-0.72$, $\mathrm{p}<0.05)$, parietal cortex $(\mathrm{r}=-0.86$, $\mathrm{p}<0.01)$, thalamus $(\mathrm{r}=-0.82, \mathrm{p}<0.01)$ and brain stem $(r=-0.82, p<0.02)$.

No further significant effects on brain POMC products, whether related to cause of death, vitamin tablet consumption, or any other measured variables were found.

\section{Discussion}

Although the highest concentrations of brain POMC products are contained in the arcuate nucleus of the hypothalamus, ${ }^{28}$ this study showed no differences in hypothalamic concentrations of the three measured peptides between controls and subjects with WernickeKorsakoff syndrome in this region. This contrasts with our earlier findings in thiamin deficient rats, where hypothalamic ACTH concentration was half that of controls. ${ }^{22}$

An earlier study of 51 cases of subjects with Wernicke-Korsakoff, however, showed that the mamillary body was the major locus of structural damage, ${ }^{29}$ being shrunken, brown, and spongy in appearance in all but one instance. Changes in the third ventricular wall and thalamus were seen less often. It is therefore of interest that mamillary body $\beta$-EP concentration was significantly affected in our study. That mamillary body $\beta$-EP seemed to increase the higher the dose of alcohol, is of further interest, and suggests that although the causative factor of Wernicke-Korsakoff is thiamin deficiency, alcohol, too, may have a large role in the changes in CNS metabolism which have such devastating effects on memory function.

An unexpected finding was that subjects with Wernicke-Korsakoff syndrome were well nourished, with normal BMIs, and that there was evidence of thiamin deficiency only in the brainstem. The value of thiamin estimation in subjects with Wernicke-Korsakoff syndrome is uncertain however, because it is routine emergency department practice to administer a large dose of thiamin to suspected cases of Wernicke- 
Korsakoff syndrome. Although none of them regularly took vitamin tablets, three of them did so occasionally. The observed negative correlations between brain thiamin and $\beta$-EP concentrations, although suggestive of an interplay between the two factors, should therefore be viewed with caution.

It should be noted that the $\beta$-endorphin assay used in this study does not distinguish between it and the related, but behaviourally inactive peptide $\beta$-LPH, nor was the methodology used here able to distinguish whether the observed increase in $\beta$-endorphin was due to increased synthesis or disturbed metabolism. In view of the lack of effect on ACTH and $\alpha-\mathrm{MSH}$, which derive from the same precursor, the latter seems the more likely mechanism.

The hypothesis that $\beta$-endorphin may have a role in the pathogenesis of Wernicke-Korsakoff syndrome, has been put forward in several publications, ${ }^{30-32}$ the authors proposing that an increase in $\beta$-endorphin concentrations in Wernicke-Korsakoff syndrome may account for some of the amnesic features of the syndrome. The only other published studies of central POMC products in alcoholics contradict this point of view, deficits of cerebrospinal fluid $\beta$-endorphin having been reported. ${ }^{33}{ }^{34}$ The assumption in these studies is that CSF peptide concentrations reflect their concentration in the brain itself, whereas in reality the situation may be more complex. In view of the present findings one possible interpretation is that ethanol interferes with normal $\beta$-EP release and metabolism, causing its concentration in the mamillary body to rise, with a corresponding fall in cerebrospinal fluid concentrations.

Our results seem to proint towards there being an aetiological role for the endorphinergic system in Wernicke-Korsakoff syndrome, and that the gradual rise in $\beta$-EP with increasing alcohol intake provides further evidence that alcohol may exert some of its reinforcing effects through endogenous opiates.

In summary, the preceding data lend support to the hypothesis that excessive $\beta$-EP activity is a contributory factor to the memory deficit in Korsakoff's psychosis, and that this excess is related to high alcohol intake. This is the first time, as far as we are aware, that an abnormality of brain neuropeptide concentrations has been reported in this disorder.

We thank Professor L H Rees and Dr P J Lowry (now Professo We thank Professor L H Rees and Dr P J Lowry (now Professor Lowry, University of Reading), Department of Chemical Endocrinology, St Bartholomew's Hospital, London, for their
generous gift of antibodies to $\beta$-endorphin and ACTH, and Dr R generous gift of antibodies to $\beta$-endorphin and ACTH, and Dr R
Davis and Mr G Icke, Haematology Department, Royal Perth Davis and Mr G Icke, Haematology Department, Royal Perth
Hospital, Western Australia, for performing thiamin estimations. Mr J Daly assisted with the collection of specimens.

1 Gianoulakis C, Chan JSD, Kalant H, Chretien M. Chronic ethanol treatment alters the biosynthesis of $\beta$-endorphin
by the rat intermediate lobe. Can J Physiol Pharmacol by the rat interme

2 Seizinger BR, Bovermann K, Hollt V, Herz A. Enhanced activity of the $\beta$-endorphinergic system in the anterior and neurointermediate lobe of the rat pituitary after chronic treatment with ethanol liquid diet. J Pharmacol Exp Ther 1984;230:455-61.

3 Gianoulakis C, Barcomb A. Effect of acute ethanol in vivo and in vitro on the $\beta$-endorphin system in the rat. Life $S c i$ 987;40:19-28.

4 Sandi C, Borrell J, Guaza C. Beta-endorphin administration interferes with the acquisition and initial maintenance of ethanol preference in the rat. Physiol Behav 1989;45 87-92.

5 Izquierdo I. Effect of beta-endorphin and naloxone on acquisition, memory and retrieval of shuttle avoidance and habituation learning in rats. Psychopharmacology 1980;69:111-15.

6 Izquierdo I, Dias RD. Effect of ACTH, epinephrine, $\beta$ endorphin, naloxone and of the combination of naloxone or $\beta$-endorphin with ACTH or epinephrine on memory or $\beta$-endorphin with ACTH or epinephrine on mem

7 Patterson TA, Schulteis G, Alvarado MC, et al. Influence of opioid peptides on learning and memory processes in the chick. Behav Neurosci 1989;103:429-37.

8 Vendite D, Rocha JB, Mello CF, Souza DO. Effects of undernutrition during suckling and of post-training betaendorphin administration on avoidance performances of adult rats. Braz J Med Biol Res 1987;20:731-40.

9 Bostock E, Gallagher M, King RA. Effects of opioid microinjections into the medial septal area on spatial memory in rats. Behav Neurosci 1988;102:643-52.

10 Zager EL, Black P McL. Neuropetides in human memory and learning processes. Neurosurgery 1985;17:355-69.

11 Morley JE. Neuropeptides, behavior and aging. $\mathrm{J} \mathrm{Am}$ Geriatr Soc 1986;34:52-62.

12 Sandman CA, Kastin AJ. The influence of fragments of the LPH chains on learning, memory and attention in animals LPH chains on learning, memory and attentic

13 Drago F, Continella G, Scapagnini U. Behavioural activity of a short chain ACTH analog. Pharmacol Biochem Behav 1984;20:689-95.

14 Sandman CA, George J, Nolan JD, van Riezen H, Kastin AJ. Enhancement of attention in man with ACTH MSH $_{4-10}$. Physiol Behav 1975;15:427-31.

15 Sandman CA, George J, McCanne TR, Nolan JD, Kaswan J, Kastin AJ. MSH/ACTH ${ }_{+10}$ influences behavioural and physiological measures of attention. J Clin Endocrinol Metab 1977;44:884-91.

16 Branconnier RJ, Cole JO, Gardos G. ACTH An $_{4-10}$ in the amelioration of neurophysiological symptomatology associated with senile organic brain syndrome. Psychopharmacology 1979;61:161-5.

17 Miller LH, Groves GA, Bopp MJ, Kastin AJ. A neuroheptapeptide influence on cognitive functioning in the elderly. Peptides 1980;1:55-7.

18 Abuzzahab FS, Will FC, Zimmerman RL. Effects of single dose $\mathrm{ACTH}_{4-10}$ versus placebo on the memory of symptomatic geriatric volunteers. J Clin Psychopharmaco 1982;2:65-9.

19 Born J, Fehm HL, Voight KH. ACTH and attention in humans: a review. Neuropsychobiology 1986;15:165-86.

20 Cuello AC. Central distribution of opioid peptides. $\mathrm{Br} \mathrm{Med}$ Bull 1983;39:11-16.

21 Victor M, Adams RD, Collins CH. The Wernicke-Korsakoff syndrome Philadelphia: FA Davies 1971.

22 Summers JA, Pullan PT, Curnow DH. Effect of thiamin deficiency on adrenocorticotrophin and vasopressin in the rat hypothalamus. Horm Metab Res 1986;18:280.

23 Krieger DT, Liotta A, Brownstein MJ. Presence of corticotrophin in brain of normal and hypophysectomised rats. Proc Natl Acad Sci USA 1977;74:648-52.

24 Rees LH, Cook DM, Kendall JW, et al. A radioimmunoassay for rat plasma ACTH. Endocrinology 1971;89: 254-61.

25 Jeffcoate WF, Rees LH, Lowry PJ, Besser GM. A specific radioimmunoassay for human $\beta$-lipotropin. $J$ Clin Endocrinol Metab 1978;47:160-7.

26 Icke GC, Davies RE. An automated microbiological assay for the measurement of thiamin in serum and ery-
throcytes. Proceedings of the Pan-Asian-Pacific Congress throcytes. Proceedings of the Pan-Asi
on Clinical Biochemistry 1982;2:60.

27 Fang SC, Butts JS. Microbiological assay method for thiamine using Lactobacillus fermenti 36 as test organism. Proc Soc Exp Biol Med 1951;78:463-6.

28 Khachaturian H, Lewis ME, Schafer MK, Watson SJ. Anatomy of the CNS opioid systems. Trends Neurosci 1985;8:111-19.

29 Harper C. Wernicke's encephalopathy: a more common disease than is realised. J Neurol Neurosurg Psychiatr 1979;42:226-31.

30 Iacono RP, Sandyk R. Thiamine deficiency and the intrinsic opioids in the Wernicke-Korsakoff syndrome. $J$ Cereb Blood Flow Metab 1986a;62:630-1.

31 Iacono RP, Sandyk R. Wernicke-Korsakoff encephalopathy and the endorphin system. Postgrad Med J1986b;62:315. and the endorphin system. Psive the Korsakoff Rsychosis? Int J Neurosci 1986:30:311-15.

33 Gennazzani AR, Nappi G, Facchinetti F, et al. Central deficiency of $\beta$-endorphin in alcohol addicts. $J$ Clin deficiency of $\beta$-endorphin in al.
Endocrinol Metab 1982;55:583-6.

34. Savoldi F, Mazzella GL, Facchinetti F, et al. Beta-endorphin, beta-lipotropin and adrencorticotropic hormone levels in cerebrospinal fluid, and brain damage in chronic alcoholics. Eur Neurol 1983;22:265-71. 